\title{
The linkage between Churg-Strauss syndrome and leukotriene receptor antagonists: fact or fiction?
}

\author{
Deanna L McDanel' \\ Barbara A Muller ${ }^{2}$ \\ 'Departments of Pharmaceutical \\ Care and ${ }^{2}$ Internal Medicine, \\ University of lowa Hospitals and \\ Clinics, lowa City, IA, USA
}

\begin{abstract}
Epidemiologic evidence has shown that the worldwide prevalence of asthma is increasing. The leukotriene receptor antagonists (LTRAs) represent a new class of therapy for asthma. They have been developed in the last decade and play a pivotal steroid-sparing role in treating the inflammatory component of asthma. Consequently, reports of Churg-Strauss syndrome (CSS), a rare form of systemic vasculitis, have been recognized as a potential side effect in individuals with moderate to severe asthma on LTRA therapy. The serious nature of this disorder is worthy of prompt recognition by clinicians and aggressive therapy to avoid the subsequent longstanding effects of vasculitis. To validate the postulated linkage between the LTRAs and CSS, this review comprehensively evaluates reported cases in the literature and supports a pathophysiological relationship between the LTRAs and the development of CSS. Keywords: asthma, Churg-Strauss syndrome, leukotrienes, leukotriene receptor antagonists, montelukast, zafirlukast
\end{abstract}

\section{Introduction}

Asthma is a chronic inflammatory disease associated with airflow obstruction that results from contraction of airway smooth muscle, increased secretion of mucus, mucosal edema, and infiltration of the airway wall by inflammatory cells, particularly eosinophils. There is increasing evidence that leukotrienes (LTs), in particular the cysteinyl leukotrienes (CysLTs), contribute to the pathophysiology of asthma (Henderson 1994; Jones and Rodger 1999). Leukotrienes are produced by a number of cells involved in the asthmatic response, including eosinophils, mast cells, monocytes, and macrophages and they are found in bronchoalveolar lavage fluid of asthmatics (Smith 1999). Their effects include bronchoconstriction, mucus secretion, vascular permeability, decreased mucociliary clearance, edema, and eosinophil recruitment to the airways, all of which culminate in chronic inflammation contributing to airway remodeling (Jones and Rodger 1999; Hallstrand and Henderson 2002).

\section{Leukotrienes}

Discovery of LTs began over 60 years ago and they were originally termed "slow reacting substance of anaphylaxis" (SRS-A) (Brocklehurst 1960). The chemical components of SRS-A were later identified as the CysLTs, which are potent mediators of airway smooth muscle contraction (Murphy et al 1979; Lewis et al 1980; Morris et al 1980). The LTs are lipoxygenase products formed from the metabolism of arachidonic acid (AA), an essential fatty acid found in the membrane of all cells (Figure 1). The LTs are synthesized by the action of key enzyme 5-lipoxygenase 


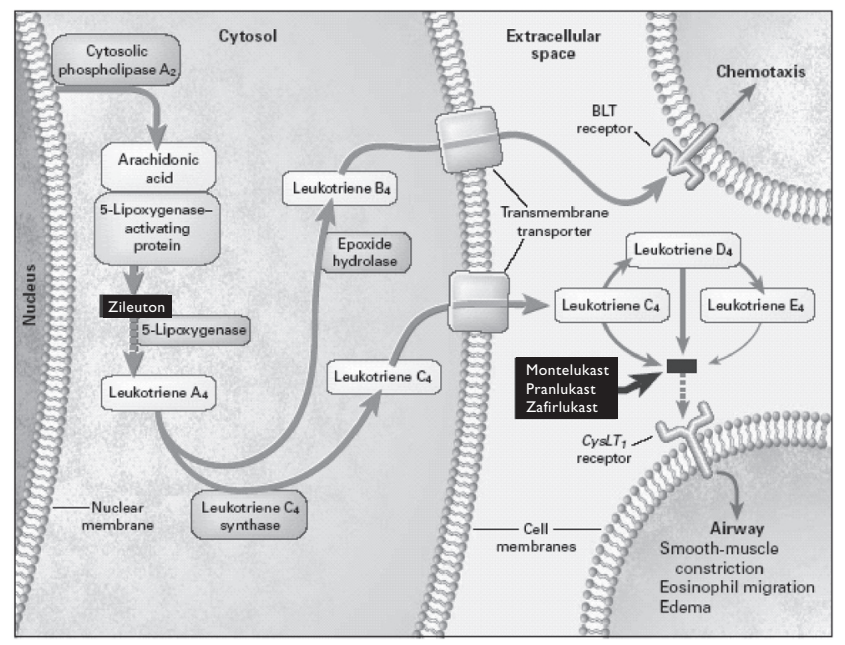

Figure I Biochemical pathways of the formation and action of the leukotrienes and sites of action of leukotriene modifying drugs. Source: Drazen JM, Israel E, O'Byrne PM. 1999. Treatment of asthma with drugs modifying the leukotriene pathway. N Engl J Med, 340:197-206. Reproduced with permission from the Massachusetts Medical Society. Copyright (C) 2005 Massachusetts Medical Society. All rights reserved.

(5-LO) on AA in the presence of 5-lipoxygenase-activating protein (FLAP) (Devillier et al 1999a; Leff 2001; Hallstrand and Henderson 2002). The biosynthesis of the LTs proceeds as a result of the sequential catalytic actions on $\mathrm{AA}$, forming leukotriene $\mathrm{A}_{4}\left(\mathrm{LTA}_{4}\right)$, leukotriene $\mathrm{B}_{4}\left(\mathrm{LTB}_{4}\right)$, leukotriene $\mathrm{C}_{4}\left(\mathrm{LTC}_{4}\right)$, leukotriene $\mathrm{D}_{4}\left(\mathrm{LTD}_{4}\right)$, and leukotriene $\mathrm{E}_{4}\left(\mathrm{LTE}_{4}\right)$. Because $\mathrm{LTC}_{4}, \mathrm{LTD}_{4}$, and $\mathrm{LTE}_{4}$ all contain the amino acid cysteine, they are collectively referred to as the cysteinyl leukotrienes (Drazen et al 1999).

\section{CysLT receptors}

The non-cysteinyl LT, $\mathrm{LTB}_{4}$, binds to the B leukotriene (BLT) receptor, which is responsible for recruitment and activation of leukocytes, in particular neutrophils (Yokomizo et al 1997; Devillier et al 1999a). Leukotriene $B_{4}$ does not appear to exert biological effects associated with asthma and acts more as a chemotactic agent. On the other hand, the cysteinyl LTs, $\mathrm{LTC}_{4}, \mathrm{LTD}_{4}$, and $\mathrm{LTE}_{4}$, are potent recruiters for eosinophils in vivo and in vitro and have been shown to mimic all the pathologic changes that are characteristic of asthma. They mediate airway smooth muscle constriction, chemotaxis, increased vascular permeability, and mucus release (Figure 2) (Piper 1983; Hay et al 1995; Hallstrand and Henderson 2002). The CysLTs exert their biologic actions by binding to two CysLT receptors, CysLT 1 and CysLT $_{2}$ (Devillier et al 1999a; Hallstrand and Henderson 2002). However, most of the actions of the CysLTs relevant to asthma are mediated through $\mathrm{CysLT}_{1}$ receptor stimulation, which is stimulated mostly by $\mathrm{LTC}_{4}$ and $\mathrm{LTD}_{4}$ (Piper 1983; Hallstrand and Henderson 2002). The CysLT 1 and $\mathrm{CysLT}_{2}$ receptors are found on multiple sites, such as airway smooth muscle, eosinophils, and macrophages (Figueroa et al 2001).

\section{Leukotriene modifiers}

The identification of SRS-A and the further detection of the CysLTs lead to a revolution in drug discovery to identify medications that could block the detrimental effects that these mediators can have on asthma, specifically through smooth airway constriction. Therefore, numerous laboratories began developing medications that could be used to inhibit these effects. A number of LT-modifier drugs have been approved in the last two decades for the therapy of asthma and represent the first new class of asthma medications within the last 30 years (Jones and Rodger 1999).

The LT modifiers comprise two pharmacologic classes of compounds, the leukotriene receptor antagonists (LTRAs) and the 5-lipoxygenase (5-LO) pathway inhibitors, or otherwise known as LT biosynthesis inhibitors. The LTRAs block the $\mathrm{CysLT}_{1}$ receptor and thus block the biological action of $\mathrm{LTC}_{4}, \mathrm{LTD}_{4}$, and $\mathrm{LTE}_{4}$. The first LTRA approved for marketing was pranlukast in 1995 (Onon ${ }^{\circledR}$; Ono Pharmaceutical Co, Ltd, Osaka City, Tokyo, Japan), followed by montelukast in 1998 (Singulair ${ }^{\circledR}$; Merck \& Co, Inc, Whitehouse Station, New Jersey, USA), then zafirlukast in 2001 (Accolate $^{\circledR}$; AstraZeneca Pharmaceuticals LP, Wilmington, Delaware, USA). The only approved LTRAs in the United Stated are montelukast and zafirlukast. Pranlukast is approved for use only in Japan. Zileuton (Zyflo ${ }^{\circledR}$; Abbott Laboratories, North Chicago, Illinois, USA)

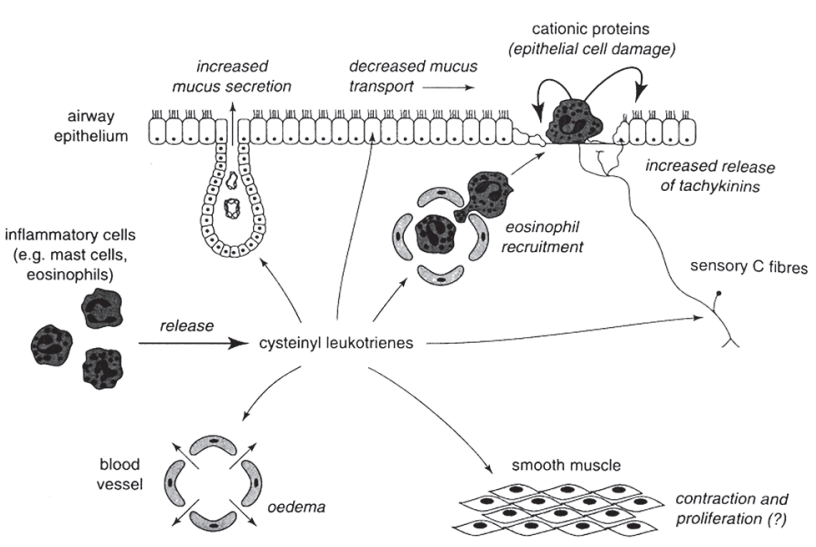

Figure 2 Potential sites and effects of cysteinyl leukotrienes relevant to a pathophysiological role in asthma. Source: Hay DWP, Torphy TJ, Undem BJ. 1995. Cysteinyl leukotrienes in asthma: old mediators up to new tricks. Trends Pharmacol Sci, 16:304-9. Reproduced with permission from Elsevier. Copyright () 2005 Elsevier. 
is the only approved inhibitor of 5-LO in the United States and it blocks the catalytic conversion of 5-lipoxygenase to both the CysLTs and $\mathrm{LTB}_{4}$. It was approved for marketing in1996, but Abbott Laboratories voluntarily withdrew it from the market in June 2003. There have been no direct comparisons between the two classes of agents, but the evidence from clinical trials has shown that zileuton has no therapeutic advantage over the LTRAs and is associated with significant liver toxicity (Pauwels 1995).

A nonselective antagonist of $\mathrm{CysLT}_{1}$ and $\mathrm{CysLT}_{2}$ and inhibitors of FLAP have been developed, but they are not yet clinically available. Selective $\mathrm{CysLT}_{2}$ receptor antagonists have not been developed. Leukotriene $B_{4}$ receptor antagonists are also not clinically available because they block experimentally-induced allergic airway inflammation in animal models, but are ineffective in blocking inflammation in patients with asthma (Hallstrand and Henderson 2002).

\section{LTRA role in asthma}

An estimated 11 million Americans, or 5\% of the general population, were reported to have asthma in the year 2000 and many are not controlled with available bronchodilators and corticosteroids (NAEPP 2002). As mentioned previously, asthma is a chronic disease of the airways that involves two basic processes: inflammation and bronchoconstriction. These processes lead to structural changes, referred to collectively as airway remodeling. Airway remodeling may or may not be a direct consequence of airway inflammation. Airway inflammation consists of eosinophils, activated Th2 lymphocytes that secrete cytokines, monocytes, and mast cells. Airway remodeling, alternatively, involves hyperplasia of goblet cells and smooth muscle, subepithelial collagen deposition, submucosal gland enlargement, and bronchial microvascular enlargement and proliferation (Bradley et al 1991). As discussed, the LT modifiers possess both bronchodilatory and antiinflammatory properties and, in addition, have been shown to increase $\mathrm{FEV}_{1}$ and peak flow rates, and to reduce asthma exacerbation rates, bronchial hyperresponsiveness, and inflammatory markers. Therefore, the LT modifiers may improve lung function and reduce symptoms in patients with asthma (Smith 1999).

The National Asthma Education and Prevention Program (NAEPP) Expert Panel from the National Heart, Lung, and Blood Institute (NHLBI) of the National Institutes of Health (NIH) has developed asthma guidelines. The guidelines were published in 1991, updated in 1997, and then selected topics were further updated in 2002 (NAEPP 1997, 2002). These guidelines divide asthma severity into four categories: mild intermittent (step 1), mild persistent (step 2), moderate persistent (step 3), and severe persistent (step 4). These severity grades allow for patient specific treatment based on their severity of asthma symptoms. Inhaled corticosteroids (ICS) are widely used to treat patients with persistent asthma and are first line treatments for steps 2 through 4.

Glucocorticosteroids (GCS) are considered potent inhibitors of the synthesis of all arachidonic acid-derived mediators, including the LTs and platelet-activating factor, and decrease the synthesis of inflammatory prostanoids (Devillier et al 1999b). However, there is data suggesting that LT concentration is not significantly affected by GCS use (Wenzel et al 1997; Pavord et al 1999). Some studies have shown that the addition of LT modifiers to ICS treatment may improve lung function and asthma control (Devillier et al 1999a). In addition, using LT modifiers in patients treated with high-dose ( $>660 \mu \mathrm{g}$ daily fluticasone or $>1200 \mu \mathrm{g}$ daily budesonide) ICS may allow up to a $50 \%$ reduction of the steroids while maintaining clinical asthma stability (Leff et al 1997; Tamaoki et al 1997). Also, according to the 1997 guidelines, the LT modifiers were considered as an alternative to low doses of ICS, cromolyn, nedocromil, or theophylline for patients $\geq 12$ years of age with uncontrolled mild persistent asthma. At that time, the guidelines mentioned that increased clinical experience and further study in a wide range of patients was necessary to establish a more specific role for LT modifiers in asthma therapy (NAEPP 1997).

The 2002 asthma guideline updates have since been published (NAEPP 2002). The most recent updates continued the same role for LT modifiers in mild persistent asthma, but added a role for them in moderate persistent asthma as alternative add-on treatment in patients inadequately controlled on low-to-medium dose $(88-660 \mu \mathrm{g}$ daily fluticasone or 200-1200 $\mu$ g daily budesonide) ICS in place of long-acting inhaled beta ${ }_{2}$-agonists or theophylline. The guidelines, however, still do not include the LT modifiers in the treatment of severe persistent asthma. Furthermore, they may have a role in patients with mild-to-moderate asthma who have adverse effects (eg, dysphonia, oropharyngeal candidiasis), or are adverse to ICS due to the potential side effects. The LT modifiers are orally administered and may increase adherence in patients who are unable to utilize inhaled medications. In addition, they provide once to twice daily dosing, have a quick onset of action (1-4 hours), and are well tolerated. They may also

Therapeutics and Clinical Risk Management 2005: I (2) 
be useful in treating patients with coexisting asthma and allergic rhinitis, treating pediatric patients with asthma, preventing exercise-induced asthma, treating aspirinsensitive asthma, reducing airway hyperresponsiveness to an allergen bronchial challenge, and they may be of some use in treating acute asthma exacerbations (Spector 1995; Wilson et al 2000; Silverman et al 2004).

Overall, LT modifiers are considered safe and effective in patients with mild to moderate persistent asthma to replace ICS or as add-on therapy as an alternative to other antiasthmatic medications. Yet, due to the onset of action taking up to 4 hours and the prolonged duration of action of the LTRAs, they should only be considered as maintenance medications, as opposed to rescue medications, in the treatment of asthma (Leff 2001). Therefore, patients with mild or moderate persistent asthma who require maintenance controller therapy may use LTRAs, but they should continue

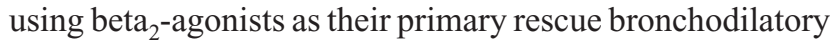
treatment. In addition, because LTRAs have been shown in clinical trials to allow steroid tapering in patients on inhaled and oral GCS, they may be highly desirable to patients chronically taking GCS to reduce potential side effects from prolonged administration of corticosteroids (Tamaoki et al 1997; Virchow et al 1997; Nayak et al 1998; Lofdahl et al 1999). Despite this benefit, there may be adverse effects in asthmatics on combination therapy with LTRA and GCS when the steroid dose is tapered.

\section{Churg-Strauss syndrome}

Churg-Strauss syndrome (CSS) is a rare disease with an incidence of 1-2 cases per million persons per year in the general population: this may range from 0.3 to 4 per million persons per year (Kurland et al 1984; Watts et al 1995; Guillevin et al 1999). However, CSS has been noted in multiple patients receiving LTRA treatment in the management of difficult to control moderate to severe asthma. Most of the reported cases of CSS in patients on LTRAs have occurred when patient's steroids were being gradually tapered or discontinued. Hence, it is unknown if CSS is a direct effect of LT inhibition or if it is due to preexisting CSS being unmasked as a result of steroid withdrawal. Therefore, further investigation into the pathophysiologic linkage between CSS and use of LTRAs is necessary.

Churg-Strauss syndrome, also known as allergic granulomatosis and angiitis, is one of multiple vasculitic diseases, termed the vasculitides. Vasculitis is a process of endothelial inflammation of blood vessels, which compromises the vessel lumen and can further result in tissue ischemia and infarction leading to necrosis, or bleeding by rupture of the blood vessel wall. Churg-Strauss syndrome is a systemic vasculitis that affects mainly the medium- and small-sized muscular arteries and is characterized with coexisting asthma, allergic rhinitis, and prominent peripheral blood eosinophilia (Lanham et al 1984). Churg-Strauss syndrome afflicts multiple organ systems, predominantly the pulmonary and cutaneous systems, causing pulmonary infiltrates, purpura, urticaria, and nodules, respectively. It may also be detrimental to the cardiovascular, nasal, gastrointestinal, renal, musculoskeletal, and central nervous systems. In addition, other constitutional symptoms may be present, such as myalgias, weight loss, fever, malaise, and headache (Guillevin et al 1999).

\section{History and diagnosis}

Jacob Churg and Lotte Strauss first described CSS in 1951, when 13 patients with severe asthma were diagnosed with allergic granulomatosis and angiitis (Churg and Strauss 1951). All of their patients had the following common histological findings: blood and tissue eosinophilia, necrotizing vasculitis, and necrotizing granulomas centered on necrotic eosinophils. These illnesses predated corticosteroid therapy, which is the preferred treatment for CSS, and so only 2 patients survived. Some 30 years later, Lanham et al (1984) reviewed 154 cases of CSS. They found that CSS could be successfully treated with corticosteroids and suggested to shift the diagnosis criteria from being purely pathologic to being more clinically centered. They proposed another classification system for CSS and were also the first to propose that CSS develops in a phasic pattern (Table 1). This sequential pattern may evolve with an early "prodromal" or "pre-vasculitic" phase, a vasculitic phase, and then finally a post-vasculitic phase. The prodromal phase usually occurs in the second and third decades of life and may be characterized by allergic rhinitis, followed by asthma and the infiltration of the blood vessels and tissues by eosinophils. Tissue eosinophilia is the diagnostic hallmark of early-stage CSS and may progress to the life-threatening vasculitic phase occurring mostly in the third and fourth decades of life (Churg 2001). This stage may be fatal if not treated promptly. The post-vasculitic phase may occur even though patients are aggressively managed. In 1995, Churg et al reaffirmed Lanham and colleagues' concept of a phasic evolution of CSS, where they reported 4 cases of asthma 
Table I Phasic pattern of developing Churg-Strauss syndrome

\begin{tabular}{lll}
\hline Pre-vasculitic phase (prodromal) & Vasculitic phase (eosinophilic) & Post-vasculitic phase \\
\hline Allergic rhinitis & Peripheral and tissue eosinophilia & End organ vasculitis \\
Sinusitis & Pulmonary infiltrates & Polyarthralgias \\
Asthma & Eosinophilic gastroenteritis & Peripheral neuropathy \\
Blood eosinophilia & Necrotizing vasculitis & Cerebral vasculitis $($ rare) \\
Tissue eosinophilia & Necrotizing granulomas & Constitutional symptoms $^{\mathrm{a}}$ \\
Myalgias and arthralgias & Constitutional symptoms &
\end{tabular}

${ }^{\text {a } C o n s t i t u t i o n a l ~ s y m p t o m s ~ m a y ~ i n c l u d e ~ s u c h ~ t h i n g s ~ a s ~ f e v e r, ~ w e i g h t ~ l o s s, ~ m a l a i s e, ~ d e c r e a s e d ~ a p p e t i t e, ~ m y a l g i a s, ~ o r ~ a r t h r a l g i a s . ~}$

and eosinophilia. These patients had varying degrees of eosinophilic tissue infiltration, which either suggested or confirmed vasculitis, and corticosteroid therapy for asthma either partially or totally suppressed some of the manifestations of CSS. They termed the incompletely evolved illnesses as formes frustes CSS (Churg et al 1995).

In addition to the 1951 Churg and Strauss and 1984 Lanham et al criterion, as seen in Table 2, there are two more recent sources that proposed more specific diagnostic criteria for CSS, the American College of Rheumatology (ACR) in 1990 and a Consensus Conference at the University of North Carolina Chapel Hill in 1994 (Masi et al 1990; Jennette et al 1994). The ACR criteria for classifying CSS are the most common criteria used to diagnose it (Masi et al 1990). The presence of 4 or more of the following criteria in a patient with documented vasculitis yields a sensitivity of $85 \%$ and a specificity of $99.7 \%$ for CSS: (1) asthma; (2) eosinophilia greater than $10 \%$ on differential white blood cell count; (3) mononeuropathy (including multiplex) or polyneuropathy; (4) migratory or transient pulmonary infiltrates detected radiographically; (5) paranasal sinus abnormality; and (6) biopsy containing a blood vessel with extravascular eosinophils.

Since these criteria have been developed, antineutrophil cytoplasmic antibody (ANCA) testing has become available and is not part of any of these diagnostic schemes. A positive ANCA is found in only $50 \%-70 \%$ of patients with CSS. There are two diagnostically valuable types of ANCA: antibodies against myeloperoxidase (MPO; p-ANCA or perinuclear ANCA) and antibodies against a $29-\mathrm{kD}$ neutrophils serine protease, p29, or proteinase 3 (PR3; c-ANCA or cytoplasmic ANCA) (Bielory et al 2001). A positive p-ANCA is found in $30 \%-60 \%$ of patients with CSS, while another $15 \%$ of patients have a positive c-ANCA. A positive c-ANCA is more commonly positive in Wegener's granulomatosis, another vasculitic disease (Hoffman and Specks 1998). A properly performed ANCA test must include an antigen-specific immunoassay (ELISA) reacting to neoantigens elaborated by the vasculitis process, which are PR3 or MPO. An accurate diagnosis of CSS is difficult because other individual manifestations of the syndrome can occur independently and can exist for many years before additional features become clinically apparent. In addition, the main pathologic features of CSS, allergic granulomatosis, vasculitis, and eosinophilia, are also features of several other diseases. Therefore, both clinical and histopathologic diagnostic criteria should be used in conjunction with an ANCA test for diagnosing CSS. These confirmatory tests can provide strong support for an accurate diagnosis of CSS, even if overt vasculitis cannot be found pathologically (Churg 2001). Lastly, other laboratory tests may help in the diagnosis, such as an erythrocyte sedimentation rate, $\mathrm{C}$-reactive protein, or eosinophil count.

Table 2 Diagnostic criteria for Churg-Strauss syndrome

\begin{tabular}{|c|c|}
\hline Reference & Criteria \\
\hline Churg and Strauss I95I & $\begin{array}{l}\text { History of asthma } \\
\text { Blood and tissue eosinophilia } \\
\text { Necrotizing vasculitis } \\
\text { Necrotizing granulomas centered on necrotic } \\
\text { eosinophils }\end{array}$ \\
\hline Lanham et al 1984 & $\begin{array}{l}\text { Asthma } \\
\text { Peripheral blood eosinophilia }\left(>1.5 \times 10^{9} / \mathrm{L}\right) \\
\text { Vasculitis involving } \geq 2 \text { extrapulmonary } \\
\text { organs }\end{array}$ \\
\hline $\begin{array}{l}\text { American College of } \\
\text { Rheumatology } \\
\text { (Masi et al 1990) }\end{array}$ & $\begin{array}{l}\text { Asthma } \\
\text { Eosinophilia }>10 \% \\
\text { Mononeuropathy (including multiplex) or } \\
\text { polyneuropathy } \\
\text { Pulmonary infiltrates } \\
\text { Paranasal sinus abnormalities } \\
\text { Biopsy containing a blood vessel with } \\
\text { extravascular eosinophils }\end{array}$ \\
\hline $\begin{array}{l}\text { University of North } \\
\text { Carolina Chapel Hill } \\
\text { Consensus Conference } \\
\text { (Jennette et al 1994) }\end{array}$ & $\begin{array}{l}\text { Asthma } \\
\text { Eosinophilia } \\
\text { Granulomatous inflammation involving the } \\
\text { respiratory tract } \\
\text { Necrotizing vasculitis }\end{array}$ \\
\hline
\end{tabular}




\section{Epidemiology and etiology}

The true incidence and epidemiology of CSS remains unclear due to the difficulty in differentiating multiple vasculitic processes into an accurate diagnosis of CSS or formes frustes CSS. Approximately $10 \%$ of patients with severe vasculitis are recognized to have CSS. Among the major vasculitides, the frequency of CSS is second only to that of Wegener's granulomatosis (Specks and DeRemee 1990). It occurs in equal frequency between men and women. The exact etiology of CSS is unknown, but it is most likely due to an autoimmune process due to the prominence of allergic features (allergic rhinitis and asthma), heightened $\mathrm{T}$ cell immunity (pulmonary angiocentric granulomatosis), altered humoral immunity (hypergammaglobulinemia, especially IgE, and elevated rheumatoid factor), and immune complex disease (vasculitis in the presence of circulating IgE-containing immune complexes and positive $\mathrm{p}$-ANCA).

\section{Treatment of CSS}

Once CSS is diagnosed, the next clinical challenge is to determine a treatment plan that will adequately treat the vasculitis. Most patients with CSS have been treated with oral or inhaled GCS for their asthma, and yet the mainstay of treatment for CSS is corticosteroid therapy.

\section{Corticosteroids}

Treatment with corticosteroids dramatically alters the course of CSS and improves overall survival. Doses usually start at $1 \mathrm{mg} / \mathrm{kg} / \mathrm{d}$ (usually $40-60 \mathrm{mg} / \mathrm{d}$ ) and are tapered over 3-6 months to approximately $10 \mathrm{mg} / \mathrm{d}$ based on the patient's clinical response. The treatment is then continued for about 12 months or until CSS has completely resolved (Guillevin et al 1996). Due to the poorer prognosis, if there is no improvement with standard doses of corticosteroids in patients with myocardial, gastrointestinal, or renal involvement, than treatment with higher doses of corticosteroids, $1-1.5 \mathrm{mg} / \mathrm{kg}$ for longer periods of time, or the addition of immunosuppressive agents is often warranted. Inhaled steroids without the need for systemic GCS may be useful for the management of upper and lower respiratory tract disease. Long-term systemic corticosteroid therapy can lead to complications, such as osteoporosis with bone fracture, infection, hypercorticism, cataracts, psychosis, hypertension, diabetes, and myopathy. Therefore, CSS patients on long-term corticosteroid therapy are recommended to take daily calcium supplements (1000-1500 mg elemental calcium per day) to prevent bone loss. Patients should be counseled appropriately and monitored for longterm side effects.

\section{Immunosuppressive therapy}

Adjunctive immunosuppressive therapy with cyclophosphamide or azathioprine to CSS has been shown to be effective in some patients, possibly through an antiinflammatory process. Cyclophosphamide is dosed orally at $2 \mathrm{mg} / \mathrm{kg} / \mathrm{d}$ or intravenously at $0.6 \mathrm{~g} / \mathrm{m}^{2}$ monthly, both for 12 months. Cyclophosphamide use does not improve survival rates, but its use is associated with a reduced incidence of relapse and an improved clinical response to treatment (Conron and Beynon 2000). Cyclophosphamide therapy, however, is associated with hemorrhagic cystitis, and urinalysis needs to be monitored periodically. If a patient develops cystitis, they should get twice-yearly urinary cytology and once-yearly cystoscopy due to the risk of bladder cancer. On the other hand, azathioprine (AZA) is less toxic than cyclophosphamide and yet provides similar protection against relapse. Therefore, as soon as stable remission is obtained, switching from cyclophosphamide to AZA is currently recommended. The doses used for AZA in CSS are similar to what is used in Wegener's granulomatosis, and in most patients azathioprine is initially given at a dose of $2 \mathrm{mg} / \mathrm{kg} / \mathrm{d}$ (Jayne et al 2003). If remission is not obtained within 6 months of cyclophosphamide in patients with severe initial disease, then they should continue cyclophosphamide until remission and for an additional few months after remission, unless toxicity is limiting further treatment. Methotrexate and mycophenolate mofetil are both advocated as alternative immunosuppressive therapy, but these agents have not been rigorously studied in treating CSS (Jamaleddine et al 2002; Assaf et al 2004). In addition, low-dose GCS ( $\leq 10 \mathrm{mg} / \mathrm{d}$ of prednisone) therapy is used for an antiinflammatory effect while on immunosuppressive therapy, but it has been suggested that concurrent use is not necessary. Therefore, because GCS are not free of side effects, it is recommended to slowly taper them off once there is a significant response to the immunosuppressive agent, which usually occurs after one month.

\section{Other therapies}

Alternative treatment options that have been used are highdose intravenous gamma globulin, interferon alpha, cyclosporine, tumor necrosis factor (TNF)-alpha blockers, and plasma exchange. These therapies are usually reserved 
for patients with severe, fulminant disease or in patients unresponsive to corticosteroids and immunosuppressive agents.

The use of high-dose intravenous immunoglobulin (IVIG) treatment has been found to be beneficial in treating CSS when other therapies fail. The mechanisms proposed for the clinical response in CSS while on IVIG include the following: increased perfusion around neurons may improve neuropathy, enhanced neuromuscular transmission and vasodilation may enhance cardiac function, and inactivation of activated eosinophils may decrease eosinophilia (Tsurikisawa et al 2004). Doses used in clinical studies include 1-6 monthly treatments of IVIG between $400 \mathrm{mg} / \mathrm{kg} / \mathrm{d}$ and $2 \mathrm{~g} / \mathrm{kg} / \mathrm{d}$ given daily for 5 days (Levy, George, et al 1999; Levy, Sherer, et al 1999; Levy et al 2003; Tsurikisawa et al 2004).

Interferon (IFN)-alpha is a cytokine that possesses potent antiviral and immunoregulatory activities. Treatment with IFN-alpha, either $2 a$ or $2 b$, may be beneficial in patients with CSS unresponsive to corticosteroids and cyclophosphamide, with infectious complications, or with prominent skin lesions, and may improve lung function. (Tatsis et al 1998; Termeer et al 2001; Simon et al 2003). Doses that were used in clinical studies range from 3 to 10 million units given 3 times per week, up to high doses such as 3-9 million units/d. Treatment duration varied, but at least 5 months of therapy was used in some studies (Simon et al 2003).

Another alternative is the use of cyclosporine, which has caused clinical remission and allowed discontinuation in GCS therapy in one patient who failed previous management with AZA and cyclophosphamide (McDermott and Powell 1998). Though not widely studied, the use of the TNF-alpha blockers, etanercept and infliximab, proved to be effective and safe in treating patients who had a severe relapse in their CSS and were refractory to cyclophosphamide and corticosteroid therapy (Arbach et al 2002). Lastly, plasma exchange has been used in conjunction with other therapies, and is designed for the removal of large molecular weight substances from the plasma to reduce further damage and permit reversal of the pathologic process. However, a meta-analysis in CSS patients found that plasma exchange added no benefit to treatment with corticosteroids, with or without cyclophosphamide (Guillevin et al 1997). Therefore, plasma exchange is not recommended routinely for management of patients with CSS.

\section{Monitoring treatment response}

Monitoring the responsiveness of CSS to treatment and recurrence/relapse of CSS is best achieved by following the eosinophil count and erythrocyte sedimentation rate. A persistent positive ANCA in CSS may be a marker of an underlying disease process, but this does not reflect disease activity adequately and should not be used to determine changes in therapy. This was demonstrated in a retrospective study of 53 patients with polyarteritis nodosa or CSS in whom the persistence of a positive ANCA did not correlate with an active underlying disease (Cohen et al 1995). Radiographic manifestations may remain stable or may rapidly regress with corticosteroid treatment. After successful response to treatment, it is very rare to have a relapse, and therefore treatment can be discontinued in most patients. However, premature withdrawal of treatment can result in recurrence and so caution should be taken with deciding when to stop therapy for CSS.

\section{Prognosis of CSS}

The prognosis of patients with CSS is unclear, but treatment may induce clinical remission in over $90 \%$ of patients and significantly decrease mortality by increasing the 5-year survival rate to $>70 \%$ (Guillevin et al 1999). However, $25 \%$ of patients may relapse when corticosteroids are tapered and over $50 \%$ of those untreated may die within 3 months. The presence or absence of certain clinical features may strongly correlate with a patient's prognosis. The following correlate to a poor prognosis: cardiac, gastrointestinal, or central nervous system involvement, renal insufficiency with serum creatinine concentration $>1.6 \mathrm{mg} / \mathrm{dL}$, or proteinuria $>1 \mathrm{~g} / \mathrm{d}$. A "five-factor score" based upon the above 5 prognostic criteria has been used to predict survival in CSS. Guillevin et al (1996) reported the following 5-year mortality figures based on one large series: $12 \%$ when none of the five prognostic factors was present, $26 \%$ when one factor was present, and $46 \%$ when three or more factors were present. Of these 5 factors, the presence of significant cardiac (eg, pericarditis, heart failure, myocardial infarction) or gastrointestinal disease (eg, abdominal pain, diarrhea, gastrointestinal bleeding, colitis) appears to be the strongest indicator of increased mortality. Also, the shorter the duration of asthma before the onset of vasculitis, the poorer the prognosis. Most deaths result from complications of the vasculitic phase of the disease, and are most commonly due to cardiac failure, myocardial infarction, cerebral 
hemorrhage, renal failure, gastrointestinal bleeding, or status asthmaticus.

\section{CSS linkage to LTRA}

Churg-Strauss syndrome is a rare disorder that has been postulated to occur in patients treated with LTRAs for asthma. It has been noted to develop in steroid-dependent asthmatic patients where their oral GCS dose was reduced as they were successfully being treated with the LTRA (ie, Wechsler et al 1998; Kinoshita et al 1999; Michael and Murphy 2003). However, though less frequently, this syndrome has also occurred when a LTRA has been substituted for inhaled corticosteroids, without a history of oral steroid withdrawal (ie, Katz and Papernik 1998; Green and Vayonis 1999; Franco and Artes 1999; Sabio et al 2001). In fact, the labeling for zafirlukast was revised after the Food and Drug Administration (FDA) received case reports of CSS in patients on zafirlukast. It now states that reducing the dose of oral steroids in patients concomitantly treated with zafirlukast has been followed by rare occurrences of eosinophilia, vasculitic rash, worsening pulmonary symptoms, cardiac complications, and/or neuropathy sometimes presenting as CSS (Formulary 1997). Multiple theories have been hypothesized to explain the possible linkage between CSS and the LTRAs, but no definitive causal link has been established.

\section{Theories}

One proposed theory to explain the association between the LTRAs and CSS is that a patient may have an underlying subclinical form of CSS, or formes frustes, and instituting therapy with LTRAs allows the tapering of GCS and thus the development of full-blown CSS (Churg et al 1995). Interestingly, a second theory is that CSS is an allergic response to therapy with LTRAs, as CSS has been shown to be a hypersensitivity reaction to different antibiotics (eg, erythromycin, azithromycin, roxithromycin) (Dietz et al 1998; Katz and Papernik 1998). However, in the reported cases through the year 2000 in patients on LTRA, development of CSS happened from 2 days to 8 months after the initiation of treatment with LTRAs, with most patients being on the LTRA for at least 2 months, which is an unusually long time for drug hypersensitivity to develop (Jamaleddine et al 2002). A third theory is based on the imbalance in leukotriene receptor stimulation (Katz and Papernik 1998). As discussed previously, these agents block the effects of the cysLTs $\left(\mathrm{LTC}_{4}, \mathrm{LTD}_{4}\right.$, and $\left.\mathrm{LTE}_{4}\right)$ but do not block the effect of $\mathrm{LTB}_{4}$, which is a chemoattractant for eosinophils and neutrophils. Thus, it has been hypothesized that LTRAs could have led to increased levels of eosinophils. However, though occurring much less frequently than with the LTRAs, CSS has been described in asthmatic patients receiving zileuton (Weller 2001). Zileuton, is a 5-LO inhibitor and thus inhibits the synthesis of $\mathrm{LTB}_{4}$ in addition to the cysLTs. Knowing this makes this prior hypothesis less credible. Regardless, there have been a large number of published cases of CSS identified since the marketing of the LTRAs (Weller 2001; Jamaleddine et al 2002). Therefore, further discussion of a possible linkage is imperative.

\section{Incidence}

The true incidence of developing CSS in patients on LTRAs is unknown. However, an estimated incidence of CSS in the asthmatic population receiving zafirlukast has been reported by Wechsler et al, when citing data on file from Zeneca Pharmaceuticals, as 60 cases per million asthmatics/ year (Wechsler et al 1999). Martin et al (1999) reported the incidence of CSS in asthmatics exposed to three non-LTRA asthma therapies (bambuterol, salmeterol, and nedocromil) as 64.4 cases per million asthmatics/year. Therefore, the incidence of CSS between asthmatics is similar whether or not they have been treated with LTRAs. Though the annual incidence of CSS in the general population may range up to 4.0 cases/million, the incidence of CSS in asthmatic patients receiving LTRAs, or other asthma therapies, is 20-fold that of the general population (Kurland et al 1984). This further supports the theory that some asthmatic patients might have preexisting CSS that is suppressed during asthma treatment with corticosteroids.

\section{Case discussion}

In 1999, Guillevin et al published a review of 96 patients with CSS between the years of 1963 and 1995, before marketing the LTRA class of medications. The authors focused on the clinical manifestations and prognostic factors of CSS in these patients. Of the patients who had a detailed clinical history ( 80 of the 96 patients), a majority of them had evidence of allergy/atopy and asthma upon diagnosis with CSS, and 33\% had pulmonary infiltrates. The proposed causes for the development of CSS were various antigenic exposures, desensitization therapy for severe asthma, and rapid discontinuation of oral corticosteroids prior to the onset of vasculitis. The 60 survivors were maintained in remission 
with chronic low dose oral corticosteroids or inhaled corticosteroids.

\section{Previously reported cases on CSS and the LTRAs}

The review by Guillevin et al (1999) shows that there have been numerous reports of CSS prior to the availability of LTRAs. However, since the marketing of the LTRAs, there have been an increasing number of reports of CSS, and therefore a particular class-effect cannot be ruled out. At a National Institute of Health (NIH) workshop in 2000, representatives from the FDA presented preliminary findings based on analyses of data from its Adverse Events Reporting System (AERS) for cases of CSS and other eosinophilic conditions associated with 5 asthma drugs (Weller 2001). These products were zafirlukast, montelukast, zileuton, fluticasone, and salmeterol. They reported on 165 case reports, with 151 patients of whom met 2 or more of the ACR criteria for CSS while on LT modifier therapy (unlike 4 criteria that are used for diagnosing CSS). Eighty-three patients were taking zafirlukast (52 also received fluticasone), 63 were taking montelukast (41 with concomitant fluticasone), and 5 were patients taking the 5-LO inhibitor zileuton ( 2 with fluticasone use). In all, 94 patients had adequate information on prior oral GCS use. Of these, $88 \%$ had developed CSS during GCS tapering, while $12 \%$ had developed CSS with no prior use or with distant ( $>1$ year) prior use of GCS.

In 2002, Jamaleddine et al published a review of all the published cases of CSS in patients on LTRAs up through October 2000, which totaled 23 cases (Jamaleddine et al 2002). Of the 23 patients discussed, 13 were treated with zafirlukast, 9 were treated with montelukast, and 1 with pranlukast. The onset of CSS occurred anywhere from 2 days to 8 months after starting treatment with LTRAs. They reported that CSS developed during the tapering of oral or inhaled steroids in 18 patients, while in 5 patients CSS manifested without concurrent tapering of steroids. Despite what the authors report, after further review of the cases, it is thought that CSS developed in GCS tapering in only 14 patients, and 9 patients did not have GCS tapering at disease onset. Five patients had formes frustes CSS, or at least 3 of the ACR criteria for classifying CSS before LTRA treatment, and these symptoms increased with concomitant steroid tapering, and CSS was diagnosed within 3 months of starting LTRAs. In regards to the ACR criteria, all 23 patients had asthma treated with inhaled or oral corticosteroids, 22 had peripheral eosinophilia, 12 had neuropathy, 21 had evidence of pulmonary infiltrates on chest radiograph, 18 patients had sinusitis or rhinitis, and histologic evidence of vasculitis was found in 15 patients. In addition, 10 patients had cardiomyopathy and 11 had cutaneous involvement.

\section{Review and analysis of all published cases of CSS and LTRAs}

In addition to the multiple reports from the FDA's AERS, since Jamaleddine and colleagues' review of cases through October 2000, we identified 27 additional case reports published in the literature of CSS in patients on montelukast, zafirlukast, and pranlukast (1 of which was from Wechsler et al in 1999 and was not discussed by Jamaleddine et al 2002). We also have had 3 patients of our own who have been diagnosed with CSS while taking LTRA for their asthma. All 53 patient cases are compared in Table 3 and will be discussed in this paper.

Of the 53 cases reviewed, 16 patients were treated with zafirlukast, 30 were treated with montelukast, 5 with pranlukast, and 2 with more than one of these agents. The age of onset of CSS ranged from 7-79 years old (mean age 47 years), with only 11 patients $<30$ years of age. There were 30 females and 23 males, therefore the distribution between the genders is similar. The onset of CSS occurred anywhere from 2 days to 4 years after starting treatment with LTRAs, with onset of CSS within 7 months of LTRA in 39 (74\%) patients (within 4 months in 24 patients).

The majority of patients used corticosteroid therapy before being diagnosed with CSS, but 4 patients have never received either oral or inhaled GCS. Thirty-seven patients had been treated with both oral and inhaled GCS for their asthma (1 patient may not have gotten ICS), while 7 patients had only been treated with ICS and 5 had only been treated with oral GCS. In the patients who had been treated with oral GCS, the time between the last oral GCS use and the diagnosis of CSS ranged from 3 days to 16 months, with 22 (42\%) patients stopping GCS in the preceding 3 months. However, this was not specified in 2 patients. Regarding the relationship of CSS to tapering corticosteroids, 21 (40\%) patients began to manifest CSS during the tapering of oral or inhaled steroids, while $31(58 \%)$ patients began to manifest CSS without concurrent tapering of steroids (in 1 patient it was not specified). In 5 patients, CSS was diagnosed while they were still on oral GCS, which were not being tapered in 3 patients.

The course of developing CSS while on LTRAs varied between patients. Eight (15\%) patients had at least 3 of the ACR criteria for classifying CSS before LTRA treatment, and therefore may have had formes frustes CSS, and the 


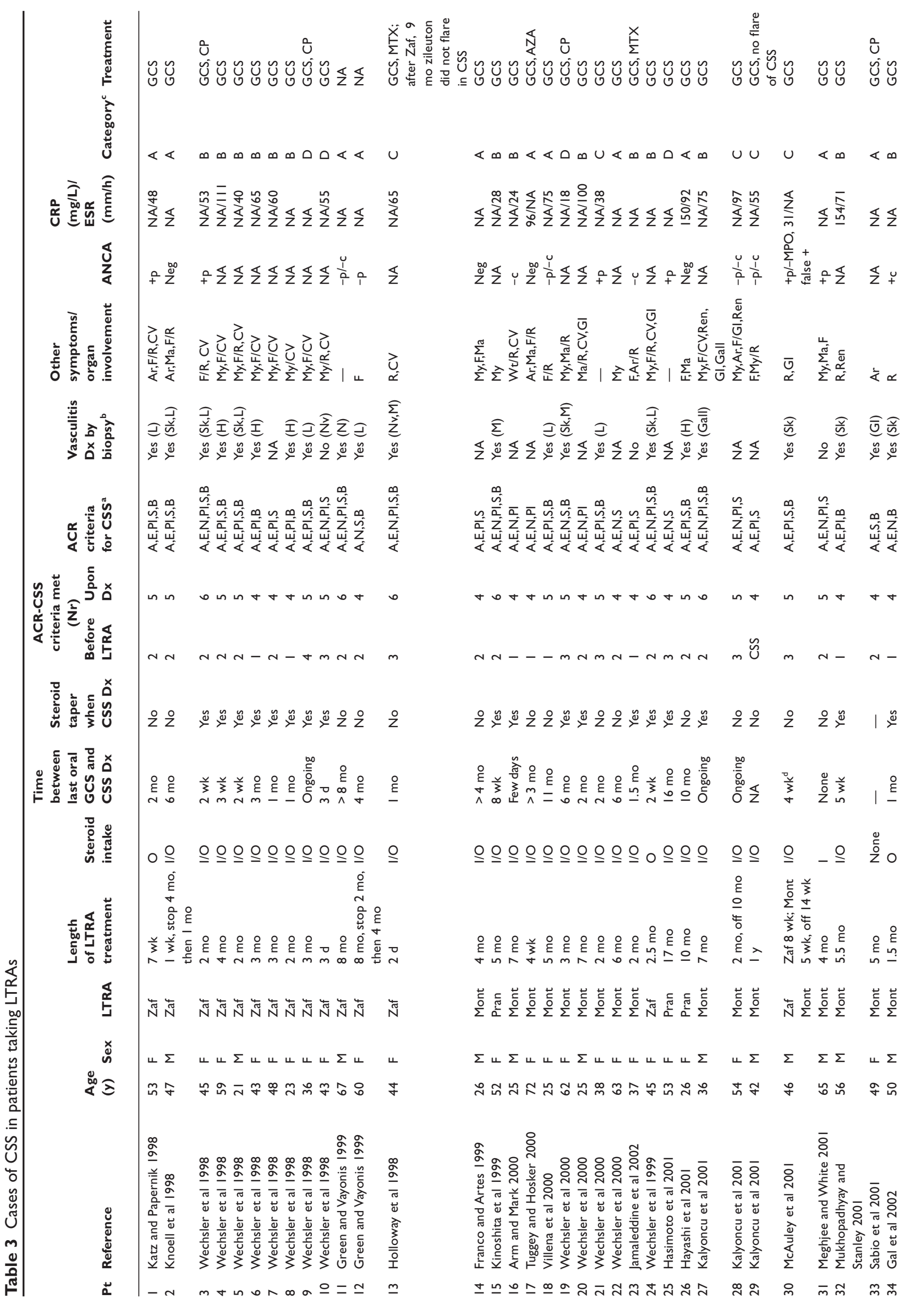




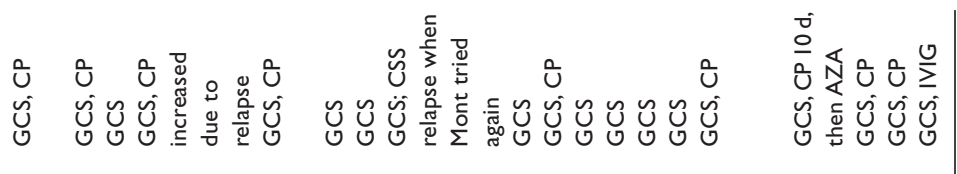

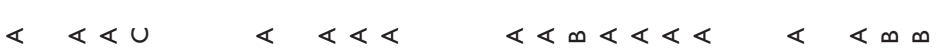

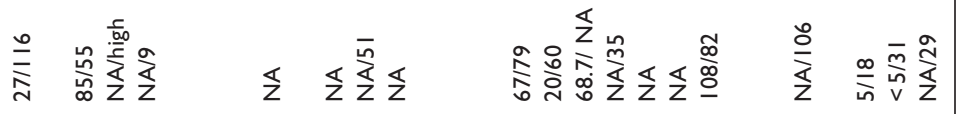

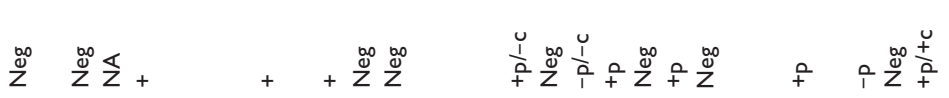

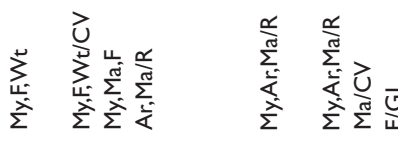

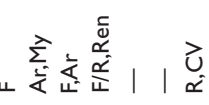

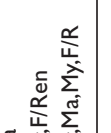

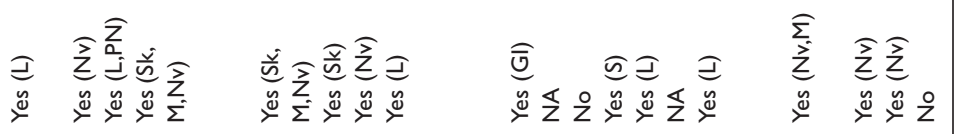

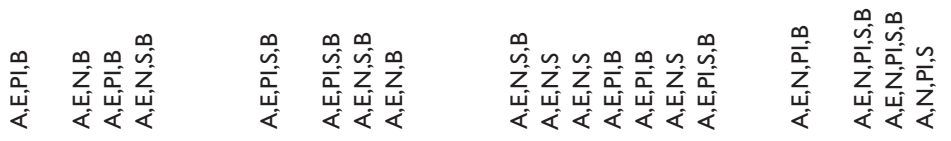

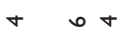

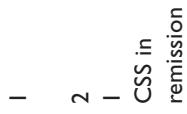

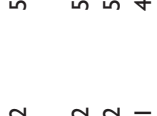

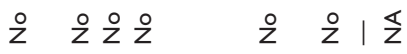

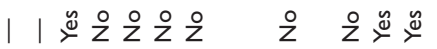

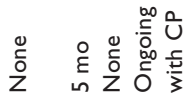

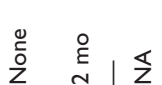

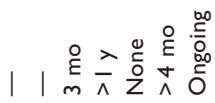

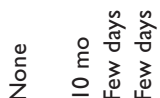

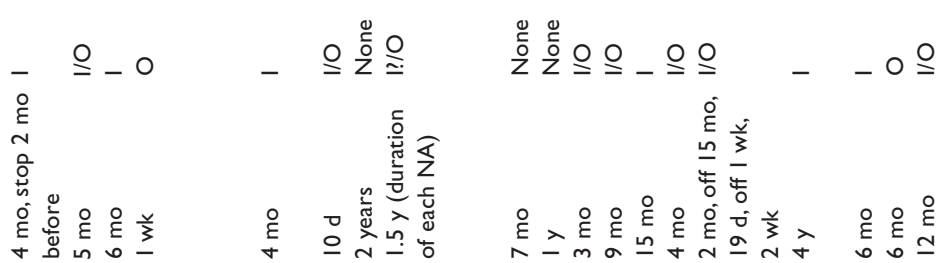

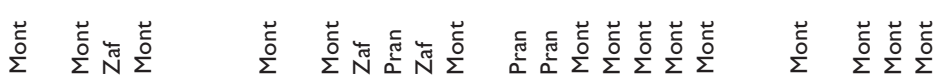

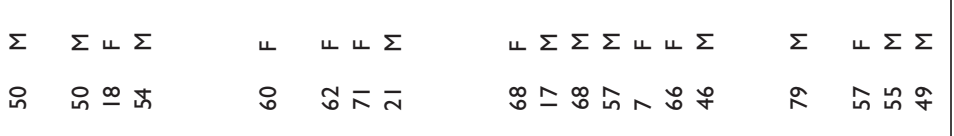

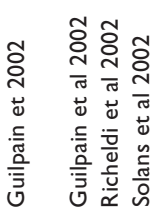

$n$
0
0

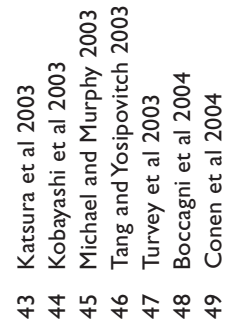

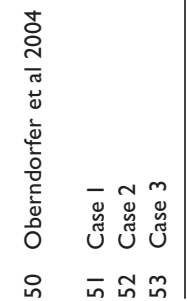

尊

永藏

突

要跣

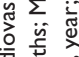

更

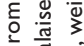

촐

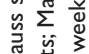

至

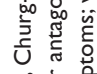

㟧

䓂 ⿺辶力

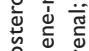

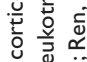

Uิ

히을

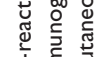

Uं

है

产

드에

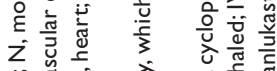

บิ

宅

을

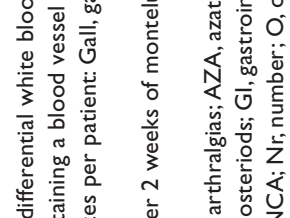

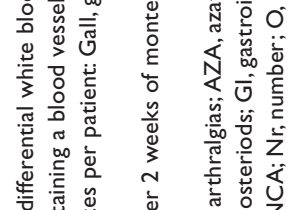

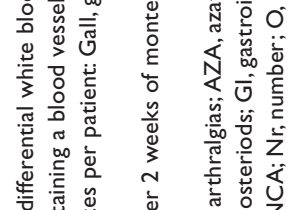

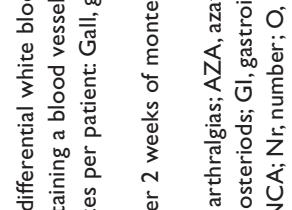

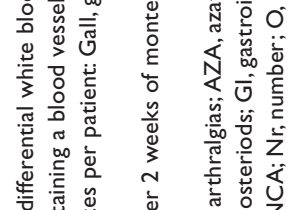

荙蓄要

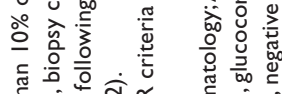

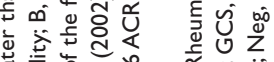

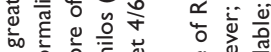

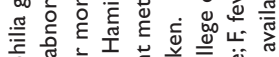

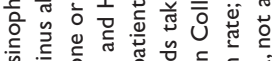

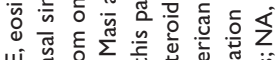

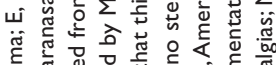

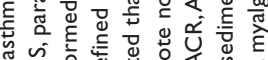

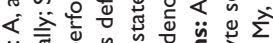

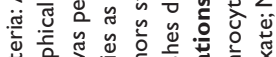

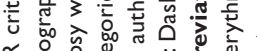

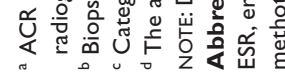


CSS symptoms increased in all 8 patients while on LTRA therapy. The diagnosis of CSS occurred during the tapering of GCS in 5 of the 8 patients with possible latent CSS. Interestingly, 2 patients had the diagnosis of CSS prior to starting the LTRA. One patient had a relapse of CSS within 1 week of starting montelukast and required an increase in the GCS and cyclophosphamide doses (Solans et al 2002), while the other patient did not have any increase in symptoms even after 1 year of montelukast therapy (Kalyoncu et al 2001). Also, one patient diagnosed with CSS after 2 days of zafirlukast therapy was started on zileuton 3 months after the diagnosis. There was no flare of CSS symptoms while on approximately 9 months of zileuton (Holloway et al 1998).

The clinical presentation, manifestations, and diagnosis of CSS were clearly individualized between patients. In regards to the ACR diagnostic criteria, all 53 patients had asthma, 51 (96\%) had peripheral eosinophilia, 29 (55\%) had neuropathy, 39 (74\%) had evidence of pulmonary infiltrates on chest radiograph, 38 (72\%) patients had paranasal sinus abnormality (ie, sinusitis or rhinitis), and $37(70 \%)$ patients had biopsy evidence of vasculitis. A total of $42(79 \%)$ patients had constitutional symptoms, including 28 patients with fever, 23 with myalgias, 13 with arthralgias, 12 with malaise, and weight loss was significant in 3 patients. Thirty-four (64\%) patients had other organ involvement, and included 23 patients with cutaneous (eg, rash), 17 patients with cardiovascular, 6 patients with gastrointestinal, 5 with renal, and 1 patient with gallbladder involvement.

Antineutrophil cytoplasmic antibody testing was used in conjunction with both clinical and histopathologic diagnostic criteria in 36 patients. Fourteen patients had a positive ANCA test, that was specified in 9 with a $(+)$ pANCA, 1 had a $(+)$ c-ANCA, and 1 had both a $(+)$ p- and $(+)$ c-ANCA (reported as a false positive in 1 patient). Otherwise, 21 had a negative test, that was specified in 2 with a (-) p-ANCA, 2 had a (-) c-ANCA, and 5 had both a $(-)$ p- and (-) c-ANCA. Ten patients had a reported elevated CRP (normal $<5-10 \mathrm{mg} / \mathrm{L}$ ) and 31 patients had a reported elevated ESR (normal $0-13 \mathrm{~mm} / \mathrm{h}$ ). Of the 51 patients in which therapy for CSS was reported, all patients received GCS. Sixteen (31\%) patients required additional immunosuppressive therapy for the CSS, and 12 were treated with cyclophosphamide (1 of which was on this prior and had the dose increased), 1 with azathioprine, 1 with cyclophosphamide for 10 days and switched to azathioprine, and 2 with methotrexate. Also, 1 patient had IVIG therapy for 1 year.
Lastly, Keogh and Specks (2003) conducted an observational study in a large series of patients with CSS to determine the association of leukotriene receptor antagonists with the course of CSS and ANCA with disease activity. They identified 91 patients by a computerized search of the Mayo Clinic Rochester database for the years 1990 to 2000. Twenty-three patients $(25 \%)$ received LTRAs (7 received montelukast, 16 received zafirlukast, and 2 received both) during the course of CSS. Of the 23 patients on LTRAs, 16 received treatment before CSS was diagnosed, 6 started LTRA in the course of CSS, and the time of use of the LTRA was unclear in 1 patient. Only 3 of the 16 patients treated with LTRA before CSS was diagnosed, had evidence of formes frustes CSS before starting LTRAs. In the 13 patients who received LTRA before the onset of symptoms, 8 developed CSS within 5 months ( 2 on LTRA $>1$ year) and 3 discontinued therapy at least 6 months before the onset of CSS. Vasculitis was related to tapering CSS on only 2 of the patients. Of the 6 patients who started LTRA therapy during remission of CSS, 4 remained in remission, but 2 developed a vasculitic relapse in association with tapering GCS.

\section{Discussion}

This article reviews all of the published cases identified by the authors of CSS in patients taking LTRAs for the purpose of further delineating if a linkage exists. From our analysis of these cases, a possible linkage is supported by the association between the use of GCS and course of disease development while on LTRAs.

An editorial by Masi and Hamilos, published in the same issue as the Jamaleddine et al review in 2002, further interprets the available data on the complex relationships between the LTRAs and the development of CSS (Masi and Hamilos 2002). The authors proposed categorizing the cases into 4 subgroups (category A, B, C, and D) as a way to assess the case reports. These subgroups are based on the temporal relationships between corticosteroid therapy, initiation of LTRA therapy, and onset of CSS. Category A included cases in which the CSS manifestations began while on LTRAs, but in the absence of GCS therapy or without any basic change in the asthma management while on LTRA (ie, tapering or discontinuation of GCS). This category could support a role for LTRAs in the evolution of CSS. Category $B$ included patients who began to manifest CSS after receiving a LTRA in the setting of either tapering or discontinuing oral or inhaled GCS therapy. The majority of 
cases reported by Jamaleddine et al (2002) fit into this category. Category $\mathrm{C}$ would include cases in which LTRAs were started in patients in the course of latent CSS, such that the patients have initial manifestations of formes frustes CSS, or CSS in remission, even without any concurrent GCS therapy or tapering/discontinuation of oral or inhaled GCS. This category of patients would suggest that the use of LTRAs was coincidental in that the drug was started in the course of evolving disease. Category D is similar to category $\mathrm{C}$, and would include patients with formes frustes CSS already present before starting LTRAs, except that CSS occurs in the setting of a tapering or discontinuation of either systemic or inhaled GCS therapy. It is most likely that these cases already had formes frustes CSS and this was unmasked by tapering the GCS rather than by the use of LTRAs. Patients in category $\mathrm{C}$ or D should no longer be considered as LTRA-induced CSS.

Compilation of the 53 cases discussed and categorizing them via the Masi and Hamilos categories may help in answering the question about a potential linkage between LTRA and CSS (Figure 3; Table 3). It is shown that 26 (49\%) patients could be classified into category A and because there were no changes or tapering in GCS therapy, there may have been an independent association between LTRAs and CSS. In contrast, 17 (32\%) patients are classified in category B and after receiving a LTRA, developed CSS during the tapering or discontinuation of GCS therapy. This category of patients may support the theory that the patient had an underlying preexisting form of CSS, characterized by a

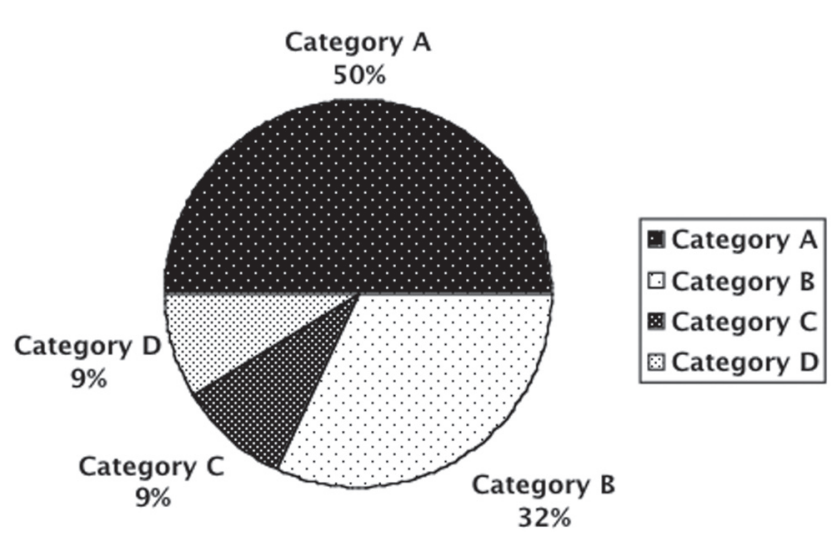

Figure 3 Categorization of cases based on the categories described by Masi and Hamilos (2002). Category A is when Churg-Strauss syndrome (CSS) manifestations began while on leukotriene receptor antagonists (LTRAs), but in the absence of glucocorticosteroid (GCS) therapy or without any basic change in the asthma management. Category B is when CSS manifested after receiving a LTRA in the setting of either tapering or discontinuing oral or inhaled GCS therapy. Category C is when LTRAs were started in the course of latent CSS, even without any concurrent GCS therapy or tapering/discontinuation of oral or inhaled GCS. Category D is when LTRAs were started in the course of latent CSS and GCS were being tapered or discontinued. history of asthma and sinusitis/rhinitis in the majority of patients, and that the development of the full-blown syndrome coincidentally occurred after the introduction of LTRAs. Of the 10 (18\%) patients with 3 or more ACR criteria prior to starting LTRA, 6 patients could be put in category $\mathrm{C}$ as they did not have concurrent GCS tapering, and 4 patients could be placed in category $\mathrm{D}$ as the full manifestation of CSS occurred during GCS tapering. It may be said with some confidence that CSS was not induced by LTRA in these last 10 patients, as it is likely they did have an underlying latent form of CSS.

Since the marketing of the LTRA in 1998, over 200 cases total of CSS in patients taking LTRAs have been reported in the literature, through the FDA's AERS, and in an observational study (Weller 2001; Keogh and Specks 2003). From this paper, it is shown that nearly $50 \%$ of published cases have shown that CSS manifests without tapering or discontinuation of GCS therapy, and therefore it can be said, though with a high degree of suspicion, that CSS may be a LTRA-induced consequence and that there may be higher risk in a select population of patients. However, with this said, it should also be mentioned that though there have been numerous cases of CSS in patients taking LTRAs, millions of asthmatic patients are effectively being treated with LTRAs. Therefore, the overall risk of developing CSS, if truly linked to the LTRAs, is small and occurs only in a minority of patients. The possible linkage, however, does deserve consideration by clinicians.

\section{Clinical impact}

Leukotriene-receptor antagonists are effective and reasonably safe agents to improve asthma control in patients uncontrolled on GCS therapy and may permit the tapering of systemic and inhaled GCS (Tamaoki et al 1997; Leff et al 1997; Spector 2001). However, the incidence of CSS is increasing and though no definitive link has been established, there have been numerous case reports of developing CSS while tapering or discontinuing oral or inhaled GCS in patients on LTRA therapy for moderate to severe persistent asthma, as seen in Table 3 (Watts et al 2000). One potential explanation of the increased incidence of CSS is that patients with latent CSS might be more likely to be treated with LTRAs, as a newer class of asthma therapy, due to the refractoriness and severity of their current asthma. On the other hand, there have also been multiple reports of CSS developing in patients taking LTRAs without concurrent GCS therapy or independent of GCS tapering/ 
discontinuation. Therefore, the association of CSS with the use of LTAs may be coincidental, yet the possibility of a direct linkage cannot be excluded. Until more definitive controlled clinical or epidemiologic data are available, prescribers should take into account the potential cause and effect relationship as described prior to initiating LTRAs in asthmatic patients.

Churg-Strauss syndrome should be suspected in patients with constitutional symptoms, such as fever, weight loss, malaise, or with increasing cough/dyspnea with decline in pulmonary function, pulmonary infiltrates in the absence of infection, eosinophilia, cardiac involvement, peripheral neuropathy, glomerulonephritis, or palpable purpura. Patients with any of these signs should be fully evaluated for the potential diagnosis of CSS. Diagnosing CSS is difficult, because there is no single definitive diagnostic test, yet using both clinical and histopathologic criteria in addition to a properly performed ANCA test and other lab tests (eg, erythrocyte sedimentation rate, C-reactive protein, and eosinophil counts) may provide substantial evidence for a diagnosis of CSS (Churg 2001). If either formes frustes CSS (Churg et al 1995) or advanced CSS is diagnosed and the patient is taking a LTRA, discontinuing the LTRA is recommended until further research can exclude with confidence a definitive linkage in the evolution of CSS.

Early recognition and treatment of CSS is essential for long-term survival and to maintain quality of life. The careful diagnosis and thorough understanding of CSS will enable clinicians to make sound treatment decisions and to provide effective care for patients with this disease.

\section{Summary}

The authors conclude that the data are suggestive of a causal linkage between LTRAs and the development of CSS. However, without prospective clinical studies, current evidence does not support a definitive association between the development of CSS and LTRA therapy. The data does suggest that the development of CSS in asthmatic patients receiving LTRAs may occur as a result of tapering corticosteroids, specifically in patients who may already have a preexisting masked form of underlying vasculitis. Healthcare providers should be aware of the warning signs of vasculitis, especially in patients with 3 or more ACR criteria that may be suggestive of formes frustes CSS, when treating atopic patients. Based on this review, the authors do not feel that clinicians should refrain from using LTRAs in treating asthma, as they provide a very effective treatment option. However, clinicians should monitor patients closely for the constellation of symptoms suggestive of latent or new onset CSS, which may occur concurrent with LTRA therapy and GCS tapering or discontinuation in moderateto-severe asthmatics.

\section{References}

Arbach O, Gross WL, Gause A. 2002. Treatment of refractory ChurgStrauss-Syndrome (CSS) by TNF-alpha blockade. Immunobiology, 206:496-501.

Arm JP, Mark EJ. 2000. Case records of the Massachusetts General Hospital. Weekly clinicopathological exercises. Case 30-2000. A 25year-old man with asthma, cardiac failure, diarrhea, and weakness of the right hand. N Engl J Med, 343:953-61.

Assaf C, Mewis G, Orfanos CE, et al. 2004. Churg-Strauss syndrome: successful treatment with mycophenolate mofetil. $\mathrm{Br} J$ Dermatol, 150:598-600.

Bielory L, Gewirtz M, Hinrichs C, et al. 2001. Asthma and vasculitis: controversial association with leukotriene antagonists. Ann Allergy Asthma Immunol, 87:274-82.

Boccagni C, Tesser F, Mittino D, et al. 2004. Churg-Strauss syndrome associated with the leukotriene antagonist montelukast. Neurol Sci, $25: 21-2$.

Bradley BL, Azzawi M, Jacobson M, et al. 1991. Eosinophils, Tlymphocytes, mast cells, neutrophils, and macrophages in bronchial biopsy specimens from atopic subjects with asthma: comparison with biopsy specimens from atopic subjects without asthma and normal control subjects and relationship to bronchial hyperresponsiveness. J Allergy Clin Immunol, 88:661-74.

Brocklehurst WE. 1960. The release of histamine and formation of a slow reacting substance (SRS-A) during anaphylactic shock. J Physiol, 151:416-35.

Cakir B, Cykert S. 2003. Asthma associated with worsening leg ulcer: a case of vasculitis in primary care. South Med J, 96:677-80.

Choi IS, Koh YI, Joo JY, et al. 2003. Churg-Strauss syndrome may be induced by leukotriene modifiers in severe asthma. Ann Allergy Asthma Immunol, 91:98.

Churg A. 2001. Recent advances in the diagnosis of Churg-Strauss syndrome. Mod Pathol, 14:1284-93.

Churg A, Brallas M, Cronin SR, et al. 1995. Formes frustes of ChurgStrauss syndrome. Chest, 108:320-3.

Churg J, Strauss L. 1951. Allergic granulomatosis, allergic angiitis, and periarteritis nodosa. Am J Pathol, 27:277-301.

Cohen P, Guillevin L, Baril L, et al. 1995. Persistence of antineutrophil cytoplasmic antibodies (ANCA) in asymptomatic patients with systemic polyarteritis nodosa or Churg-Strauss syndrome: follow-up of 53 patients. Clin Exp Rheumatol, 13:193-8.

Conen D, Leuppi J, Bubendorf L, et al. 2004. Montelukast and ChurgStrauss syndrome. Swiss Med Wkly, 134:377-80.

Conron M, Beynon HLC. 2000. Churg-Strauss syndrome. Thorax, 55: 870-7.

Devillier P, Baccard N, Advenier C. 1999a. Leukotrienes, leukotriene receptor antagonists and leukotriene synthesis inhibitors in asthma: an update. Part I: synthesis, receptors and role of leukotrienes in asthma. Pharmacol Res, 40:3-13.

Devillier P, Baccard N, Advenier C. 1999b. Leukotrienes, leukotriene receptor antagonists and leukotriene synthesis inhibitors in asthma: an update. Part II: clinical studies with leukotriene receptor antagonists and leukotriene synthesis inhibitors in asthma. Pharmacol Res, 40: $15-29$.

Dietz A, Hubner C, Andrassy K. 1998. Macrolide antibiotic-induced vasculitis (Churg-Strauss syndrome). Laryngorhinootologie, 77 : 111-14. 
Drazen JM, Israel E, O’Byrne PM. 1999. Treatment of asthma with drugs modifying the leukotriene pathway. $N$ Engl J Med, 340:197-206.

Figueroa DJ, Breyer RM, Defoe SK, et al. 2001. Expression of the cysteinyl leukotriene 1 receptor in normal human lung and peripheral blood leukocytes. Am J Respir Crit Care Med, 163:226-33.

Formulary. 1997. Accolate, labeling notes possible association with ChurgStrauss syndrome. Formulary, 32:894-5.

Franco J, Artes MJ. 1999. Pulmonary eosinophilia associated with montelukast. Thorax, 54:558-60.

Gal AA, Morris RJ, Pine JR, et al. 2002. Cutaneous lesions of ChurgStrauss syndrome associated with montelukast therapy. Br J Dermatol, 147:618-19.

Green RL, Vayonis AG. 1999. Churg-Strauss syndrome after zafirlukast in two patients not receiving systemic steroid treatment. Lancet, 353:725-6.

Guillevin L, Cevallos R, Durand-Gasselin B, et al. 1997. Treatment of glomerulonephritis in microscopic polyangiitis and Churg-Strauss syndrome. Indications of plasma exchanges, meta-analysis of 2 randomized studies on 140 patients, 32 with glomerulonephritis. Ann Med Interne (Paris), 148:198.

Guillevin L, Cohen P, Gayraud M, et al. 1999. Churg-Strauss syndrome. Clinical study and long-term follow-up of 96 patients. Medicine (Baltimore), 78:26-37.

Guillevin L, Lhote F, Gayraud M, et al. 1996. Prognostic factors in polyarteritis nodosa and Churg-Strauss syndrome. Medicine (Baltimore), 75:17-28.

Guilpain P, Viallard JF, Lagarde P, et al. 2002. Churg-Strauss syndrome in two patients receiving montelukast. Rheumatology, 41:535-9.

Hallstrand TS, Henderson WR Jr. 2002. Leukotriene modifiers. Med Clin North Am, 86:1009-33.

Hashimoto M, Fujishima T, Tanaka H, et al. 2001. Churg-Strauss syndrome after reduction of inhaled corticosteroid in a patient treated with pranlukast for asthma. Intern Med, 40:432-4.

Hay DWP, Torphy TJ, Undem BJ. 1995. Cysteinyl leukotrienes in asthma: old mediators up to new tricks. Trends Pharmacol Sci, 16:304-9.

Hayashi S, Furuya S, Imamura H. 2001. Fulminant eosinophilic endomyocarditis in an asthmatic patient treated with pranlukast after corticosteroid withdrawal. Heart, 86:261.

Henderson WR Jr. 1994. The role of leukotrienes in inflammation. Ann Intern Med, 121:684-97.

Hoffman GS, Specks U. 1998. Antineutrophil cytoplasmic antibodies. Arthritis Rheum, 41:1521-37.

Holloway J, Ferriss J, Groff J, et al. 1998. Churg-Strauss syndrome associated with zafirlukast. J Am Osteopath Assoc, 98:275-8.

Jamaleddine GW, Diab KA, Tabbarah Z, et al. 2002. Leukotriene antagonists and the Churg-Strauss syndrome. Semin Arthritis Rheum, $31: 218-27$.

Jayne D, Rasmussen N, Andrassy K, et al. 2003. A randomized trial of maintenance therapy for vasculitis associated with antineutrophil cytoplasmic autoantibodies. $N$ Engl J Med, 349:36.

Jennette JC, Falk RJ, Andrassy K, et al. 1994. Nomenclature of systemic vasculitides. Proposal of an international consensus conference. Arthritis Rheum, 37:187-92.

Jones TR, Rodger IW. 1999. Role of leukotrienes and leukotriene receptor antagonists in asthma. Pulm Pharmacol Ther, 12:107-10.

Kalyoncu A, Karakaya G, Sahin A, et al. 2001. Experience of 10 years with Churg-Strauss syndrome: an accompaniment to or a transition from aspirin-induced asthma? Allergol Immunopathol, 29:185-90.

Katsura T, Yoshida F, Takinishi Y. 2003. The Churg-Strauss syndrome after pranlukast treatment in a patient not receiving corticosteroids. Ann Intern Med, 139:387.

Katz RS, Papernik M. 1998. Zafirlukast and Churg-Strauss syndrome. JAMA, 279:1949.

Keogh KA, Specks U. 2003. Churg-Strauss syndrome: clinical presentation, antineutrophil cytoplasmic antibodies, and leukotriene receptor antagonists. Am J Med, 115:284-90.
Kinoshita M, Shiraishi T, Koga T, et al. 1999. Churg-Strauss syndrome after corticosteroid withdrawal in an asthmatic patient treated with pranlukast. J Allergy Clin Immunol, 103:534-5.

Knoell DL, Lucas J, Allen JN. 1998. Churg-Strauss syndrome associated with zafirlukast. Chest, 114:332-4.

Kobayashi S, Ishizuka S, Tamura N, et al. 2003. Churg-Strauss syndrome (CSS) in a patient receiving pranlukast. Clin Rheumatol, 22:491-2.

Kurland LT, Chuang TY, Hunder G. 1984. The epidemiology of systemic arthritis. In Lawrence RC, Shulman LP, eds. The epidemiology of the rheumatic diseases. New York: Gower. p 196-205.

Lanham JG, Elkon KB, Pusey CD, et al. 1984. Systemic vasculitis with asthma and eosinophilia: a clinical approach to the Churg-Strauss syndrome. Medicine (Baltimore), 63:65-81.

Leff AR. 2001. Antileukotriene Working Group. Discovery of leukotrienes and development of antileukotriene agents. Ann Allergy Asthma Immunol, 86:4-8.

Leff JA, Israel E, Noonan MJ, et al. 1997. Montelukast (MK-0476) allows tapering of inhaled corticosteroids (ICS) in asthmatic patients while maintaining clinical stability. Am J Respir Crit Care Med, 155:A976.

Levy Y, George J, Fabbrizzi F, et al. 1999. Marked improvement of ChurgStrauss vasculitis with intravenous gammaglobulins. South Med J, 92:412-14.

Levy Y, Sherer Y, George J, et al. 1999. Serologic and clinical response to treatment of systemic vasculitis and associated autoimmune disease with intravenous immunoglobulin. Int Arch Allergy Immunol, 119: 231-8.

Levy Y, Uziel Y, Zandman GG, et al. 2003. Intravenous immunoglobulins in peripheral neuropathy associated with vasculitis. Ann Rheum Dis, 62:1221-3.

Lewis RA, Austen KF, Drazen JM, et al. 1980. Slow reacting substances of anaphylaxis: identification of leukotrienes $\mathrm{C}-1$ and $\mathrm{D}$ from human and rat sources. Proc Natl Acad Sci USA, 77:3710-14.

Lofdahl CG, Reiss TF, Leff JA, et al. 1999. Randomised, placebo controlled trial of effect of a leukotriene receptor antagonist, montelukast, on tapering inhaled corticosteroids in asthmatic patients. $B M J, 319$ : $87-90$.

Martin RM, Wilton LV, Mann RD. 1999. Prevalence of Churg-Strauss syndrome, vasculitis, eosinophilia and associated conditions: retrospective analysis of 58 prescription-event monitoring cohort studies. Pharmacoepidemiol Drug Saf, 8:179-89.

Masi AT, Hamilos DL. 2002. Leukotriene antagonists: bystanders or causes of Churg-Strauss syndrome? Semin Arthritis Rheum, 31:211-17.

Masi AT, Hunder GG, Lie JT, et al. 1990. The American College of Rheumatology 1990 criteria for the classification of Churg-Strauss syndrome (allergic granulomatosis and angiitis). Arthritis Rheum, 33:1094-100.

McAuley DF, McGovern V, Dick PT, et al. 2001. Churg-Strauss syndrome associated with leukotriene receptor antagonists. Ulster Med J, 70: $152-4$.

McDermott EM, Powell RJ. 1998. Cyclosporin in the treatment of ChurgStrauss syndrome. Ann Rheum Dis, 57:258-9.

Meghjee SPL, White JS. 2001. Montelukast and Churg-Strauss syndrome. Thorax, 56:244.

Michael AB, Murphy D. 2003. Montelukast-associated Churg-Strauss syndrome. Age Ageing, 32:551-2.

Morris HR, Taylor GW, Piper PJ, et al. 1980. Structure of slow-reacting substance of anaphylaxis from guinea pig. Nature, 285:104-6.

Mukhopadhyay A, Stanley NN. 2001. Churg-Strauss syndrome associated with montelukast. Postgrad Med J, 77:390-1.

Murphy RC, Hammarstrom S, Samuelsson B. 1979. Leukotriene C, a slowreacting substance from murine mastocytoma cells. Proc Nat Acad Sci USA, 76:4275-9.

[NAEPP] National Asthma Education and Prevention Program. 1997. Expert Panel Report 2: Guidelines for the Diagnosis and Management of Asthma. US Dept of Health, Education, and Welfare publication NIH 97-40051A. Bethesda: National Institutes of Health; National Heart, Lung, and Blood Institute. 
[NAEPP] National Asthma Education and Prevention Program. 2002. Expert Panel Report: Guidelines for the Diagnosis and Management of Asthma Update on Selected Topics-2002. US Dept of Health, Education, and Welfare publication NIH 97-4051. Bethesda: National Institutes of Health; National Heart, Lung, and Blood Institute.

Nayak AS, Anderson PL, Charous BL, et al. 1998. Equivalence of adding zafirlukast versus double-dose inhaled corticosteroids in asthmatic patients symptomatic on low-dose inhaled corticosteroids. Presented at the 54th Annual Meeting of the American Academy of Allergy, Asthma and Immunology. 1998 Mar 13-18; Washington, DC, USA.

Oberndorfer S, Beate U, Sabine U, et al. 2004. Churg Strauss syndrome during treatment of bronchial asthma with a leucotriene receptor antagonist presenting with polyneuropathy. Neurologia, 19:134-8.

Pauwels RA. 1995. Leukotrienes as therapeutic target in asthma. Allergy, 50:615-22.

Pavord ID, Ward R, Woltmann G, et al. 1999. Induced sputum eicosanoid concentrations in asthma. Am J Respir Crit Care Med, 160:1905-9.

Piper PJ. 1983. Pharmacology of leukotrienes. Br Med Bull, 39:255-9.

Richeldi L, Rossi G, Ruggieri MP, et al. 2002. Churg-Strauss syndrome in a case of asthma. Allergy, 57:647-8.

Sabio JM, Jimenez-Alonso J, Gonzalez-Crespo F. 2001. More about ChurgStrauss syndrome and montelukast treatment. Chest, 120:2116.

Silverman RA, Nowak RM, Korenblat PE, et al. 2004. Zafirlukast treatment for acute asthma: evaluation in a randomized, double-blind, multicenter trial. Chest, 126:1480-9.

Simon HU, Seelbach H, Ehmann R, et al. 2003. Clinical and immunological effects of low-dose IFN-alpha treatment in patients with corticosteroidresistant asthma. Allergy, 58:1250-5.

Smith LJ. 1999. Pharmacology and safety of the leukotriene antagonists. Clin Rev Allergy Immunol, 17:195-212.

Solans R, Bosch JA, Selva A, et al. 2002. Montelukast and Churg-Strauss syndrome. Thorax, 57:183-5.

Specks U, DeRemee RA. 1990. Granulomatous vasculitis, Wegener's granulomatosis and Churg-Strauss syndrome. Rheum Dis Clin North Am, 16:377.

Spector SL. 1995. Leukotriene inhibitors and antagonists in asthma. Ann Allergy Asthma Immunol, 75:463-73.

Spector SL. 2001. Antileukotriene Working Group. Safety of antileukotriene agents in asthma management. Ann Allergy Asthma Immunol, 86:18-23.

Tamaoki J, Kondo M, Sakai N, et al. 1997. Leukotriene antagonist prevents exacerbation of asthma during reduction of high-dose inhaled corticosteroid. The Tokyo Joshi-Idai Asthma Research Group. Am J Respir Crit Care Med, 155:1235-40.

Tang MB, Yosipovitch G. 2003. Acute Churg-Strauss syndrome in an asthmatic patient receiving montelukast therapy. Arch Dermatol, 139:715-18
Tatsis E, Schnabel A, Gross WL. 1998. Interferon-alpha treatment of four patients with the Churg-Strauss syndrome. Ann Intern Med, 129: $370-4$.

Termeer CC, Simon JC, Schopf E. 2001. Low-dose interferon alfa-2b for the treatment of Churg-Strauss syndrome with prominent skin involvement. Arch Dermatol, 137:136-8.

Tsurikisawa N, Taniguchi M, Saito H, et al. 2004. Treatment of ChurgStrauss syndrome with high-dose intravenous immunoglobulin. Ann Allergy Asthma Immunol, 92:80-7.

Tuggey JM, Hosker HSR. 2000. Churg-Strauss syndrome associated with montelukast therapy. Thorax, 55:805-6.

Turvey SE, Vargas SO, Phipatanakul W. 2003. Churg-Strauss syndrome in a 7-year-old receiving montelukast and inhaled corticosteroids. Ann Allergy Asthma Immunol, 90:274.

Villena V, Hidalgo R, Sotelo MT, et al. 2000. Montelukast and ChurgStrauss syndrome. Eur Respir J, 15:626.

Virchow JC, Hassall SM, Summerton L, et al. 1997. Improved asthma control over 6 weeks with Accolate (zafirlukast) in patients on highdose inhaled corticosteroids. J Invest Med, 45:286A.

Watts RA, Carruthers DM, Scott DGI. 1995. Epidemiology of systemic vasculitis: changing incidence of definition? Sem Arthritis Rheum, 25:28-34

Watts RA, Lane SE, Bentham G, et al. 2000. Epidemiology of systemic vasculitis: a ten-year study in the United Kingdom. Arthritis Rheum, 43:414-19.

Wechsler ME, Finn D, Gunawardena D, et al. 2000. Churg-Strauss syndrome in patients receiving montelukast as treatment for asthma. Chest, 117:708-13.

Wechsler ME, Garpestad E, Flier SR, et al. 1998. Pulmonary infiltrates, eosinophilia, and cardiomyopathy following corticosteroid withdrawal in patients with asthma receiving zafirlukast. JAMA, 279:455-7.

Wechsler ME, Pauwels R, Drazen JM. 1999. Leukotriene modifiers and Churg-Strauss syndrome: adverse effect or response to corticosteroid withdrawal? Drug Safety, 4:241-51.

Weller PF. 2001. The relationship of asthma therapy and Churg-Strauss syndrome: NIH workshop summary report. J Allergy Clin Immunol, 108:175-83.

Wenzel SE, Szefler SJ, Leung DY, et al. 1997. Bronchoscopic evaluation of severe asthma. Persistent inflammation associated with high dose glucocorticoids. Am J Respir Crit Care Med, 156:737-43.

Wilson AM, Orr LC, Sims EJ, et al. 2000. Antiasthmatic effects of mediator blockade versus topical corticosteroids in allergic rhinitis and asthma. Am J Respir Crit Care Med, 162:1297-301.

Yokomizo T, Izumi T, Chang K, et al. 1997. A G-protein-coupled receptor for leukotriene $\mathrm{B}_{4}$ that mediates chemotaxis. Nature, 387:620-4. 